\title{
New Coordinate System by Using Five Geodetic Projections in One Zone
}

\author{
Mohammed Sabri Akresh
}

\begin{abstract}
The modern technologies and developments in computers and Global Positioning System (GPS) as well as Geographic Information System (GIS), become very important in present time in mapping and coordinate system.

This paper presents a new system of coordinates by a harmonic equations "United projections", who have five projections (Mercator, Lambert, Russell, Lagrange, and the compound of the projection) in one zone coordinate system width 12 degrees, also it has 3 degrees for overlap between zones, as well as five standards parallels for zone from equator to 75 North (South).

Also this paper presents two cases; first case is to compare distances between the new coordinate system and UTM, second case creating local coordinate system for city of Hong-Kong for measuring the distances directly from rectangular coordinates using Mercator, Lambert and UTM projection. All results compared by geodesy indirect problems.
\end{abstract}

Index Terms-Harmonic equations, coordinate system, projections, algorithms and parallels

\section{INTRODUCTION}

The theory of united projections was introduced by prof. Vladimir Podshivalov in 1998, it was aimed for special cases (constructions system coordinates for GIS for countries by $12 \times 12$ degrees long and width of zone); In 2009-2012 Dr Akresh found the general law for indirect algorithms for five projections, general law for direct algorithms of Russell projection and also for Lagrange projection; The theory is completed for use as new system coordinates for world.

The theory of united projections has local system for big cities; the local system has an advantage in decreasing of distances distortion and very easy to go back to the general of coordinate system.

\section{Methodology}

The methodology in new coordinate system divides all world to 30 zones, width of each zone 12 degrees direct of parallel and long of zone begin from equator to 75 degrees (north or south) any zone has central meridian that divides zone into two conformal sections; Also the zone has five standards parallels for five projections (Mercator, Lambert, Russell, Lagrange, and the compound of the projection), as well as overlapping 5 degrees between zones near equator and 3 degrees near polar; However Fig. 1 illustrates the proposal.

The projection of Mercator is the main for five

Manuscript received March 27, 2013; revised June 15, 2013.

The author is with Civil Engineering, University of Tripoli, Libya (email: sab20084@mail.ru). projections because it has overlapping between standards parallels, while four projections (Lambert, Russell, Lagrange, and the compound of the projection) they have systems of coordinates for counties only, and theory are related by Mercator projection through standards parallels, and they haven't overlapping between standards parallels.

The main Mercator projection can be used to determine rectangular coordinates from geographic coordinates that uses statement if in ATH LAB program or other programs, for example if $0<\varphi<33$ go to $B_{1}$ (first standard parallel), if $33<\varphi<49$ go to $B_{2} \ldots$; after the determined value standard parallel can be uses for main Mercator projection [1]-[4].

For determined geographic coordinates from rectangular coordinates can be used statement if $0<(x / a)<0.57521$ go to $B_{1}, x$ - rectangular coordinate direct of north or south, $a$ earth's polar semi-axis, if $0.57521<(x / a)<0.85401$ go to $B_{2} \ldots$...

Geodetic projections divide into two methods: direct problem and indirect problem as follows.

Direct method; the method uses geographic coordinate transformation $(\varphi, \lambda)$ to rectangular coordinate in $(x, y)$; the fundamentals of equations are as follows:

$$
\left.\begin{array}{l}
x=X_{0}+C_{1} P_{1}+C_{2} P_{2}+C_{3} P_{3}+\ldots \\
y=Y_{0}+C_{1} Q_{1}+C_{2} Q_{2}+C_{3} Q_{3}+\ldots
\end{array}\right\},
$$

where $X_{0}, Y_{0}=$ initials coordinates systems for zone projection [2], [3];

$C_{j}=$ coefficients expansion of projection by direct method [2], [4];

$P_{j}, Q_{j}=$ elements of harmonic multinomial equations apply to Laplace equations.

An initial coordinates systems for zone projection; can be found from meridian arc, and parallels ellipsoid [1], [2], [4].

$$
\begin{gathered}
X_{0}=n_{1} B_{p}-n_{2} \sin 2 B_{p}+n_{3} \sin 4 B_{p}- \\
-n_{4} \sin 6 B_{p}+n_{5} \sin 8 B_{p}-\ldots \\
P_{j}=P_{j-1} P_{1}-Q_{j-1} Q_{1}, \quad P_{0}=1 \\
Q_{j}=P_{j-1} Q_{1}+Q_{j-1} P_{1}, \quad Q_{0}=0
\end{gathered}
$$

where $P_{j}=$ different values between latitudes;

$Q_{j}=$ different values between longitudes.

The different values between latitudes may be calculated from $q$ (isometric latitude), and difference between longitudes begin from $L_{c}$ (center meridian) the given meridian; isometric latitude value can be computed from the following equation (1), (2). 


$$
q=\ln \sqrt{\left(\frac{1+\sin B}{1-\sin B}\right)\left(\frac{1-e \sin B}{1+e \sin B}\right)^{e}}
$$

The difference between five projections by harmonic equations "united projections" (Mercator, Lambert, Russell, Lagrange and compound projection) is only in coefficients, where any their have special coefficients; here will use Mercator projection for direct coefficients are as following:

$$
\begin{aligned}
& C_{1}=\frac{m_{0} \cdot c \cdot \cos B_{0}}{V}, \quad C_{2}=-\frac{C_{1} \cdot \sin B_{0}}{2}, \\
& C_{3}=\frac{C_{1} \cdot \cos ^{2} B_{0}}{6}\left(\tan ^{2} B_{0}-V^{2}\right), \\
& C_{12}=\ldots \\
& C_{1}^{\prime}=\frac{1}{C_{1}}, \quad C_{2}^{\prime}=-\frac{C_{2}}{C_{1}^{3}}, \quad C_{3}^{\prime}=\frac{1}{C_{1}^{5}}\left(2 C_{2}^{2}-C_{1} C_{3}\right), \\
& C_{4}^{\prime}=\frac{1}{C_{1}^{7}}\left(-5 C_{2}^{3}-C_{1}^{2} C_{4}+5 C_{1} C_{2} C_{3}\right) \text {, } \\
& C_{j}=\ldots \ldots \ldots \ldots \ldots \ldots \ldots \ldots \ldots \ldots \ldots \ldots \ldots \ldots \ldots \ldots \ldots \ldots
\end{aligned}
$$

For all coefficients Mercator, Lambert, Russell, Lagrange and compound projection see references [2], [4], [5].

Indirect method; the method uses rectangular coordinate transformation $(\mathrm{x}, \mathrm{y})$ to geographic coordinate $(\varphi, \lambda)$; the Fundamentals equations are as following:

$$
\begin{gathered}
q=q_{0}+\sum_{j=1}^{n} C_{j}^{\prime} P_{j}^{\prime} \\
L=L_{0}+\sum_{j=1}^{n} C_{j}^{\prime} Q_{j}^{\prime} \\
P_{j}^{\prime}=P_{j-1}^{\prime} P_{1}^{\prime}-Q_{j-1}^{\prime} Q_{j-1}^{\prime}, \\
Q_{j}^{\prime}=P_{j-1}^{\prime} Q_{1}^{\prime}+Q_{j-1}^{\prime} P_{1}^{\prime}, \quad P_{0}^{\prime}=1
\end{gathered}
$$

Indirect coefficients for all projections can be computed form references [1], [2],[6].

For all coefficients see references [1], [2]. where determined geographic latitude can be uses iteration value by following equation

$$
B=2 \arctan \left[\sqrt{\left(\frac{1+e \sin B}{1-e \sin B}\right)^{e}} \times \exp (q)\right]-\frac{\pi}{2}
$$

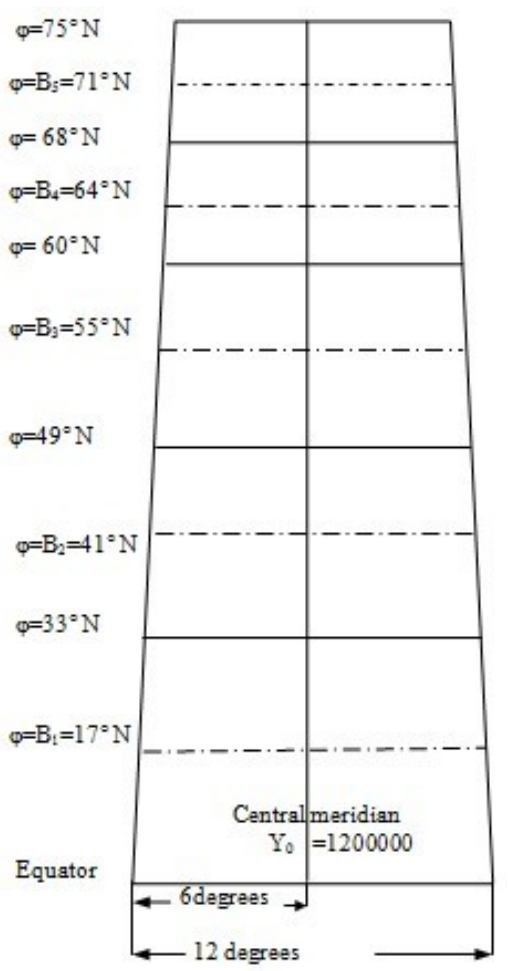

Fig. 1. Main mercator projection by standards parallels

Fig. 1 illustrates zone for Main Mercator Projection by standards Parallels, where it has false $\mathrm{Y}_{0}$ coordinate in center meridian $1200,000.000 \mathrm{~m}$ and it increases in the east direction, while it decreases in the west direction; B1,B2,...B5 standards parallels use for find rectangular coordinates(direct method) and geographic coordinates (indirect method).

\section{CASE STUDY}

Here will be study two cases; first case for new coordinate system, second case local coordinate system for city Hong-Kong.

\section{A. First Case for New Coordinate System}

The first case can be calculated some geographic coordinates $(\varphi, \lambda)$ between standards parallels in zone; and also translation to rectangular coordinates in number of zone $25\left(108^{\circ} \mathrm{E}-120^{\circ} \mathrm{E}\right)$, the digital numbers of zones same of method in UTM only here width of each zone $12^{\circ}$; from Table I follows:

TABLE I: ANALYSIS RESULTS BETWEEN PROJECTIONS

\begin{tabular}{lrcccc}
\hline \hline \multicolumn{5}{c}{ Ellipsoid parameters WGS $84 \mathrm{a}=6378137.00 \mathrm{~m}, \mathrm{~b}=6356752.314 \mathrm{~m}$} \\
\hline \hline
\end{tabular}


Table I shows results for tree projections. Projection Mercator has overlapping between standards parallels in each zone and can be calculated points from two parallels by the same results. The accuracy $0.002 \mathrm{~m}$ of Projection Mercator, this accuracy is enough (the accuracy of GPS near to $0.005 \mathrm{~m})$.

Projection of Lambert and Russell give very good results near Equator better than of Mercator. The best results for decreasing of curves and parallels distortions can be used as standard of parallel near Equator.

\section{B. Second Case Local Coordinate System for City Hong- Kong}

The Position of geographic territory of city Hong-Kong nearly $\varphi_{\mathrm{S}}=22^{\circ} 10^{\prime} 06^{\prime \prime} \mathrm{N}, \varphi_{\mathrm{N}}=22^{\circ} 36^{\prime} 13^{\prime \prime} \mathrm{N}, \lambda_{\mathrm{W}}=113^{\circ} 47^{\prime} 21^{\prime \prime} \mathrm{E}$, $\lambda_{\mathrm{E}}=114^{\circ} 28^{\prime} 48^{\prime \prime} \mathrm{E}$; as that the position of Hong-Kong in universal transverse Mercator UTM between zones 49-50; However, the study will be between traditional UTM, a new theory has been for appeared distortion of distances.

The local system gives a good results in the present time and the local coordinate system determine rectangular coordinate system for each city within high accuracy in distances measurements " without Sampson correction method", and it's equal distances measured by indirect geodetic problems.

The relation between local system and general system see Fig. 2 as follows [2], [4]:

$$
\begin{aligned}
& d X=\frac{m_{0}}{m_{0}^{\prime}} d x, \quad d Y=\frac{m_{0}}{m_{0}^{\prime}} d y, \\
& X=X_{0}+d X, \quad Y=Y_{0}+d Y
\end{aligned}
$$

where: $m_{0}$ - ideal scale factor for main projection; $m_{0}$ - ideal scale factor for local projection

$X_{0}, Y_{0}$ - initials coordinates systems for main projection; $d x, d y$-coordinates system for local projection;

$d X, d Y$ - coordinates system for main projection.

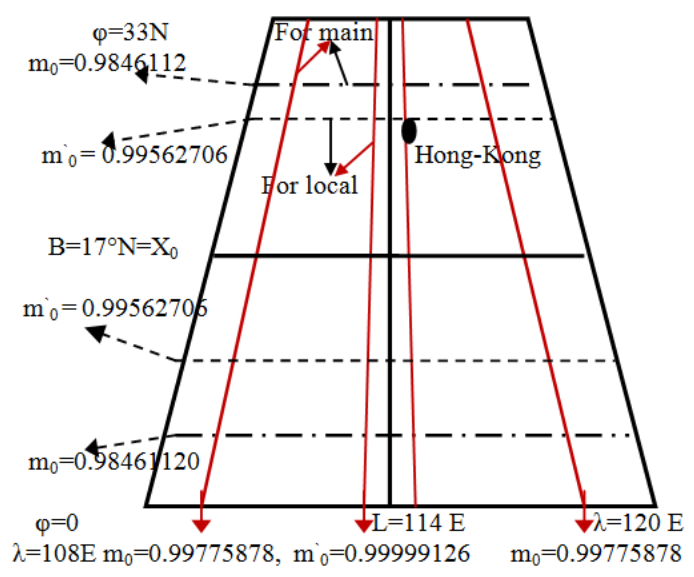

Fig. 2. Projection of Mercator and Lambert with locals systems

Fig. 2 Illustrates two projections Mercator and Lambert by mains cases and locals cases for city of Hong Kong; Black lines represent minimum distortion of distances for Lambert projection $\mathrm{m}_{0}=0.98461120$ for main and $\mathrm{m}_{0}=0.99562706$ for local system; Red lines represent min distortion of distances for Mercator projection $\mathrm{m}_{0}=0.99775878$ for main and $\mathrm{m}_{0}=0.99999126$ for local system.

\begin{tabular}{|c|c|c|c|}
\hline \multicolumn{4}{|c|}{ Projection of Lambert- Local coordinate system for city Hong-Kong $\mathrm{X}_{0}=1880307.1584 \mathrm{~m}, \mathrm{~m}_{0}=0.98461120, \mathrm{Y}_{0}=1200000 \mathrm{~m} \mathrm{~m}_{0}=0.99562706$} \\
\hline points & $\begin{array}{c}\text { A } \\
\varphi=22^{\circ} 23^{\prime} 45^{\prime \prime} \mathrm{N}, \lambda=114^{\circ} 11^{\prime} 30^{\prime \prime} \mathrm{E}\end{array}$ & $\begin{array}{c}\mathrm{B} \\
\varphi=22^{\circ} 23^{\prime} 45^{\prime \prime} \mathrm{N}, \\
\lambda=114^{\circ} 21^{\prime} 27^{\prime \prime} \mathrm{E}\end{array}$ & $\begin{array}{c}\mathrm{C} \\
\varphi=22^{\circ} 18^{\prime} 45^{\prime \prime} \mathrm{N} \\
\lambda=114^{\circ} 11^{\prime} 30^{\prime \prime} \mathrm{E}\end{array}$ \\
\hline $\mathrm{X}$ - meters & 2475912.23 & 2475936.158 & 2466684.247 \\
\hline $\mathrm{Y}$ - meters & 1219738.011 & 1236815.666 & 1219747.036 \\
\hline $\mathrm{m}_{0}{ }_{0}$ point & 1.00007591 & 1.00007591 & 0.99993838 \\
\hline$S$ - form $X, Y$ & $\mathrm{~S}_{\mathrm{A}-\mathrm{B}}=17077.671 \mathrm{~m} \quad \pm 1.295 \mathrm{~m}$ & $\begin{aligned} \mathrm{S}_{\mathrm{B}-\mathrm{C}} & =19414.840 \mathrm{~m} \\
& \pm 0.136 \mathrm{~m}\end{aligned}$ & $\begin{aligned} \mathrm{S}_{\mathrm{C}-\mathrm{A}} & =9227.987 \mathrm{~m} \\
& \pm 0.063 \mathrm{~m}\end{aligned}$ \\
\hline S- from I. G.P & $\mathrm{S}_{\mathrm{A}-\mathrm{B}}=17076.376 \mathrm{~m}$ & $\mathrm{~S}_{\mathrm{B}-\mathrm{C}}=19414.704 \mathrm{~m}$ & $\mathrm{~S}_{\mathrm{C}-\mathrm{A}}=9227.924 \mathrm{~m}$ \\
\hline \multicolumn{4}{|c|}{$\begin{array}{l}\text { Projection of Mercator - Local coordinate system for city Hong-Kong } \mathrm{X}_{0}=1880307.1584 \mathrm{~m}, \mathrm{~m}_{0}=0.99775878,, \mathrm{Y}_{0}=1200000 \mathrm{~m}, \\
\mathrm{~m}_{0}=0.99999126\end{array}$} \\
\hline & A & B & $\mathrm{C}$ \\
\hline $\mathrm{X}$ - meters & 2477639.63 & 2477670.81 & 2468411.75 \\
\hline Y - meters & 1219736.369 & 1236812.741 & 1219748.11 \\
\hline $\mathrm{m}^{\prime}{ }_{0}$ point & 0.9999961 & 1.000008 & 0.9999961 \\
\hline$S$ - form $X, Y$ & $\begin{aligned} \mathrm{S}_{\mathrm{A}-\mathrm{B}} & =17076.400 \mathrm{~m} \\
& \pm 0.024 \mathrm{~m}\end{aligned}$ & $\begin{aligned} \mathrm{S}_{\mathrm{B}-\mathrm{C}} & =19414.732 \mathrm{~m} \\
& \pm 0.028 \mathrm{~m}\end{aligned}$ & $\begin{aligned} \mathrm{S}_{\mathrm{C}-\mathrm{A}} & =9227.887 \mathrm{~m} \\
& \pm 0.037 \mathrm{~m}\end{aligned}$ \\
\hline S- from I. G.P m & $\mathrm{S}_{\mathrm{A}-\mathrm{B}}=17076.376 \mathrm{~m}$ & $\mathrm{~S}_{\mathrm{B}-\mathrm{C}}=19414.704 \mathrm{~m}$ & $\mathrm{~S}_{\mathrm{C}-\mathrm{A}}=9227.924 \mathrm{~m}$ \\
\hline \multicolumn{4}{|c|}{ projection UTM Mercator $\mathrm{m}_{0}=0.9996$ zone 50} \\
\hline & A & $\mathrm{B}$ & $\mathrm{C}$ \\
\hline $\mathrm{X}$ - meters & 2479342.604 & 2479032.759 & 2470110.439 \\
\hline Y - meters & 210850.086 & 227933.441 & 210677.842 \\
\hline $\mathrm{m}_{0}{ }_{0}$ point & 1.00063312 & 1.00051463 & 1.00063436 \\
\hline $\mathrm{S}$ - form $\mathrm{X}, \mathrm{Y}$ & $\begin{aligned} \mathrm{S}_{\mathrm{A}-\mathrm{B}} & =17086.165 \mathrm{~m} \\
& \pm 9.789 \mathrm{~m}\end{aligned}$ & $\begin{aligned} \mathrm{S}_{\mathrm{B}-\mathrm{C}} & =19425.846 \mathrm{~m} \\
& \pm 11.142 \mathrm{~m}\end{aligned}$ & $\begin{aligned} \mathrm{S}_{\mathrm{C}-\mathrm{A}} & =9233.772 \mathrm{~m} \\
& \pm 5.848 . \mathrm{m}\end{aligned}$ \\
\hline S- from I.G.P m & $\mathrm{S}_{\mathrm{A}-\mathrm{B}}=17076.376 \mathrm{~m}$ & $\mathrm{~S}_{\mathrm{B}-\mathrm{C}}=19414.704 \mathrm{~m}$ & $\mathrm{~S}_{\mathrm{C}-\mathrm{A}}=9227.924 \mathrm{~m}$ \\
\hline
\end{tabular}

TEBLE II: LOCALS SYSTEMS AND UTM, ANALYSIS RESULTS 
Table II illustrates the analysis of results between Lambert projection- locals systems and UTM; where Locals systems give a good results and better than of UTM.

\section{CONCLUSION}

The new coordinate system by five projections with locals systems better than of old coordinates systems by traditional projections "UTM, LCP" for countries and world, and results follows.

- The new coordinate system by five projections has an advantage of decreasing distances distortions and better than of UTM;

- Lambert projection and Russell best near equator as that decreased of curves parallels distortions;

- The new coordinate system by five projections can be securing the marines transportation and marines navigation;

- The local coordinates systems give high resolution for detecting positions.

\section{REFERENCES}

[1] M. S Akresh, "Development of scientific and technical foundations and technology of forming a coordinate system for geographic information systems in the Libya," Ph.D dissertation, Dept. applied geodesy, Polotsk State Univ., Novopolotsk, Belarus, 2010.

[2] M. Akresh, Advance Geodesy and Cartographic for GIS, 1st ed. Aalmustakbe, Libya, 2012, pp. 23-185.

[3] V. Morozov, Course Spheroid Geodesy, 2nd ed. Nedra, Ministry of Education, Moscow, 1979, pp. 213-253.

[4] U. Padshyvalau, The Theoretical Basis for Forming Coordinate Environment for GIS, 1st ed. PSU, Novopolotsk, 1998, pp. 8-52.

[5] M. Akresh, "New methodology for direct algorithms in russell projection-stereographic projection," Journal of Earth Science and Engineering, David publishing company, vol. 2, no. 4, pp. 253-256, April 2012.

[6] M. S Akresh, "New method in map projection indirect coefficients," in Proc.12th AGILE International Conference on Geographic Information Science and ISPRS, Hannover, June 5-7, 2009.

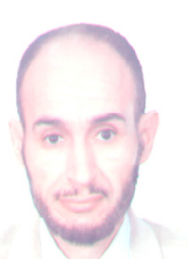

Mohammed Sabri Ali Akresh is staff member at University of Tripoli, Engineering Faculty, Civil Engineering; Bachelor B.sc and and master M.sc 1993 from Baku Faculty, Majoring in Hydrographic 5.00 score of 5.00; Master M.sc 1999 from University of Tripoli, Majoring in High Geodesy 3.7 score of 4.00; Ph.D 2010 from Polotsk State UniversityBelarus, majoring in advanced Geodesy 4.9 score of 5.0 ; he is now working for degree of doctor of sc. 